\title{
Quantitative Polymerase Chain Reaction Detection of Microchimerism in Female Transplant Renal Recipients
}

\author{
Donata Villari ${ }^{a}$ Francesca Salvianti $^{b}$ Maria Zanazzi ${ }^{c}$ Alberto Martini ${ }^{d}$ \\ Pietro Spatafora ${ }^{a}$ Simone Caroassai Grisanti ${ }^{a}$ Arcangelo Sebastianelli ${ }^{\mathrm{a}}$ \\ Giulio Nicita ${ }^{e}$ Sergio Serni ${ }^{a}$ Pamela Pinzani ${ }^{b}$
}

aDepartment of Minimally Invasive and Robotic Urologic Surgery and Kidney Transplantation, Careggi Hospital, University of Florence, Florence, Italy; ${ }^{b}$ Molecular and Clinical Biochemistry Unit, Department of Experimental and Clinical Biomedical Sciences "Mario Serio," Careggi Hospital, University of Florence, Florence, Italy; 'Renal Unit, Careggi Hospital,

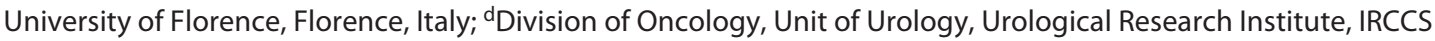

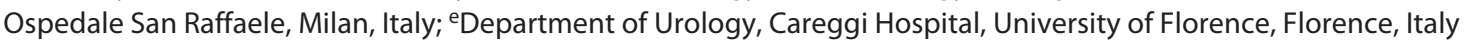

\section{Keywords}

Renal transplantation - Kidney transplantation •

Transplantation · Microchimerism - qPCR detection ·

Chimerism

\begin{abstract}
Introduction: Microchimerism (MC) is the presence of a small amount of foreign cells or DNA within a person's circulation or tissues. It has been identified also in recipients of solid organ transplants where it seems to be critical for the development and maintenance of immunological tolerance. Nevertheless, natural and/or iatrogenic MC can be acquired prior to transplantation, through pregnancy and/or blood transfusion. Objective: The aim of this study was to detect the presence of $\mathrm{MC}$ in women after renal transplantation from male cadaveric donors and its relationship with graft outcomes. Methods: We studied by qPCR the presence of the DYS14 gene sequence of the $Y$ chromosome in $12 \mathrm{fe}-$ males who received a kidney graft from a male donor before transplantation (T0), after 15 days (T1) and 1 year of trans-
\end{abstract}

plantation (T2). We found the sequence in all recipients after renal transplantation. Results: All the women were negative for this sequence prior to transplantation (T0). Mean (SD) Yrelated DNA quantity was $0.80(0.69) \mathrm{ng} / \mathrm{mL}$ plasma and 0.15 (0.26) ng/mL plasma at T1 and T2, respectively. No acute rejection was observed, and mean (SD) estimated $\mathrm{Cr}$ clearance was 68.8 (16.9) $\mathrm{mL} / \mathrm{min}$ within 1 year from transplantation. Conclusions: Presence of MC was associated with good kidney graft outcomes after 1 year of transplantation, but further studies will be needed to investigate the relationship between clinical outcomes and the development of MC in renal transplant recipient.

(c) 2020 S. Karger AG, Basel

\section{Introduction}

Microchimerism (MC) is defined as the presence of a small amount of foreign cells or DNA within a person's circulation or tissues $[1,2]$ and can be acquired after a pregnancy or blood transfusions. In 1998, Lo et al. [3]

karger@karger.com
www.karger.com/uin
Karger $\stackrel{\text { 'l/ }}{\leftarrow}$


Table 1. Demographic and medical data of RTRs (from July 2012 to June 2016)

Total RTRs, $n$

127

Males, $n(\%)$

$79(62.2)$

Females, $n(\%)$

$48(37.8)$

$2.8(1.04)$

$55(13.2)$

$54(13.3)$

IN, NA, CGN, and ADPKD

RTRs, renal transplant recipients; SD, standard deviation; IN, interstitial nephropathy; NA, nephroangiosclerosis; CGN, chronic glomerulonephritis; ADPKD, autosomal dominant polycystic kidney disease.

showed that donor-derived DNA sequences could be detected in the plasma of transplant recipients. This group further showed that different transplanted organs - for example, heart, liver and kidney - appeared to release different amounts of DNA into the circulation $[3,4]$. The presence of small amount of foreign cell or DNA within a person's circulation or tissue occurs at levels below those detectable by flow cytometry $(<1 \%)$ that can be detected by more sensitive methods such PCR is referred to as MC [5]. However, they have led to contrasting results since many different techniques and different control time points have been used to detect donor cells $[6,7]$. It is fundamental to reach agreement about molecular MC detection techniques in order to assure comparability of results. In a longitudinal follow-up study of transplant recipients, the amount of $\mathrm{MC}$ was noted to have great variation in patients after different posttransplantation periods [8]. The role of MC in renal allograft adaption and rejection varies in different clinicopathological settings and sex chromosomal MC in renal allograft [9]. The aim of the present study was to analyze cell-free DNA (cfDNA) circulating in the blood of renal transplant recipients (RTRs) in order to evaluate the clinical impact of quantitative measurement of donor MC for possible tolerance mechanism purposes. Since cfDNA is released into the bloodstream mainly for cell death via apoptosis/ necrosis [10], we hypothesized that in female RTRs Y chromosome related circulating DNA can derive only from the male transplanted organ through the same mechanisms and therefore can be a marker of rejection. We assessed the frequency of MC in serial samples, before transplantation and after 15 days. We examined its influence on clinical course over a 12-month follow-up period and whether the presence of MC can be related to signs of rejection. The pretransplant blood sample is an important control; it means that women were negative for circulating male DNA in their plasma from a prior male pregnancy.

\section{Materials and Methods}

From July 2012 to June 2016, 127 patients (79 males, $48 \mathrm{fe}$ males) underwent cadaveric renal transplantation in our Institution; cohort details are reported in Table 1 . Out of the 48 females RTRs, 25 patients received a kidney graft from a male donor. Patients with a previous renal transplant and with lost data at follow-up were excluded. Twelve patients entered in the study and were prospectively evaluated. All subjects gave informed consent; the study had the approval by the institutional review board and followed the Declaration of Helsinki. They all underwent their first renal transplantation from a cadaveric male donor.

All patients received induction therapy (basiliximab) and were on immunosuppressive therapy based on triple drug association, according to our protocol. Immunosuppression included induction with the anti-CD25 monoclonal antibody basiliximab and a triple therapy with cyclosporine (CyA), methylprednisolone (CS), and EVR (Certican) or alternatively a triple therapy with CyA, CS, and MPA (Myfortic).

Nine RTRs received maintenance immunosuppressive therapy based on CyA, CS, and MPA. CyA was started at $6 \mathrm{mg} / \mathrm{kg} /$ day in 2 separated doses, targeting whole blood was through levels of 150$300 \mathrm{ng} / \mathrm{mL}$ until month 6 after Tx and 70-150 ng/mL thereafter. MPA was administered $1.44 \mathrm{~g}$ /day in 2 divided doses (group with CyA, MPA, and CS). The standard of care was a renal biopsy for graft dysfunction, which was defined as a $>20 \%$ increase in serum Cr levels.

RTRs were prospectively studied by using a qPCR method for MC observation in plasma cfDNA based on the detection of the DYS14 gene sequences on the Y chromosome. The presence of Yrelated DNA sequences can be considered as a cell death marker released from necrotic or apoptotic cells in the transplanted organ or donor-derived hemopoietic cells in the recipient's blood or other organs. Persistence of donor DNA in recipient plasma samples was assessed at 15 days (T1) and 12 months after transplantation (T2). A pretransplant blood sample was collected from each patient to serve as an individual control (T0). Moreover, we collected data on graft loss, renal function (serum $\mathrm{Cr}$ and eClC according to Cockroft Gault formula $[11,12])$ and the occurrence of acute rejection.

\section{DNA Extraction and Quantification of Total cfDNA}

Peripheral blood was collected in an EDTA tube, transported within $1 \mathrm{~h}$ to the laboratory and centrifuged twice at $4^{\circ} \mathrm{C}$ for $10 \mathrm{~min}$ (1,600 and 14,000 rcf), in order to avoid contaminating DNA deriving from WBCs [13], according to the recently published guidelines from the Biological Stain Commission [14]. Plasma aliquots were stored at $-80^{\circ} \mathrm{C}$ before use. DNA was extracted from $500 \mu \mathrm{L}$ of plasma, using the QIAamp DSP Virus Kit (Qiagen, Italy) and RNAse digestion to prevent RNA interference during assay reaction. 
Table 2. Demographic, clinical, and laboratory parameters of patients enrolled

\begin{tabular}{ll}
\hline Parameter(s) & Value(s) \\
\hline Age at transplantation, mean (SD), years & $52.7(10.9)$ \\
Median (range) dialytic time, months & $24(0-180)$ \\
Immunosuppressive therapy & CyA, CS, and MPA/EVR \\
Serum Cr at 1 year, mean (SD), mg/dL & $1.13(0.35)$ \\
Clearance Cr/24 h at 1 year, mean (SD), mL/min & $68.8(16.9)$ \\
Blood transfusion before transplant, median (range), units & $2(0-10)$ \\
Mean (SD) DNA at 15 days, ng/mL - genome equivalents/mL (SD) & $0.80(0.69)-121.8(104.8)$ \\
Mean (SD) DNA at 1 year, ng/mL - genome equivalents/mL (SD) & $0.15(0.26)-23.1(40.0)$ \\
\hline
\end{tabular}

$\mathrm{SD}$, standard deviation.

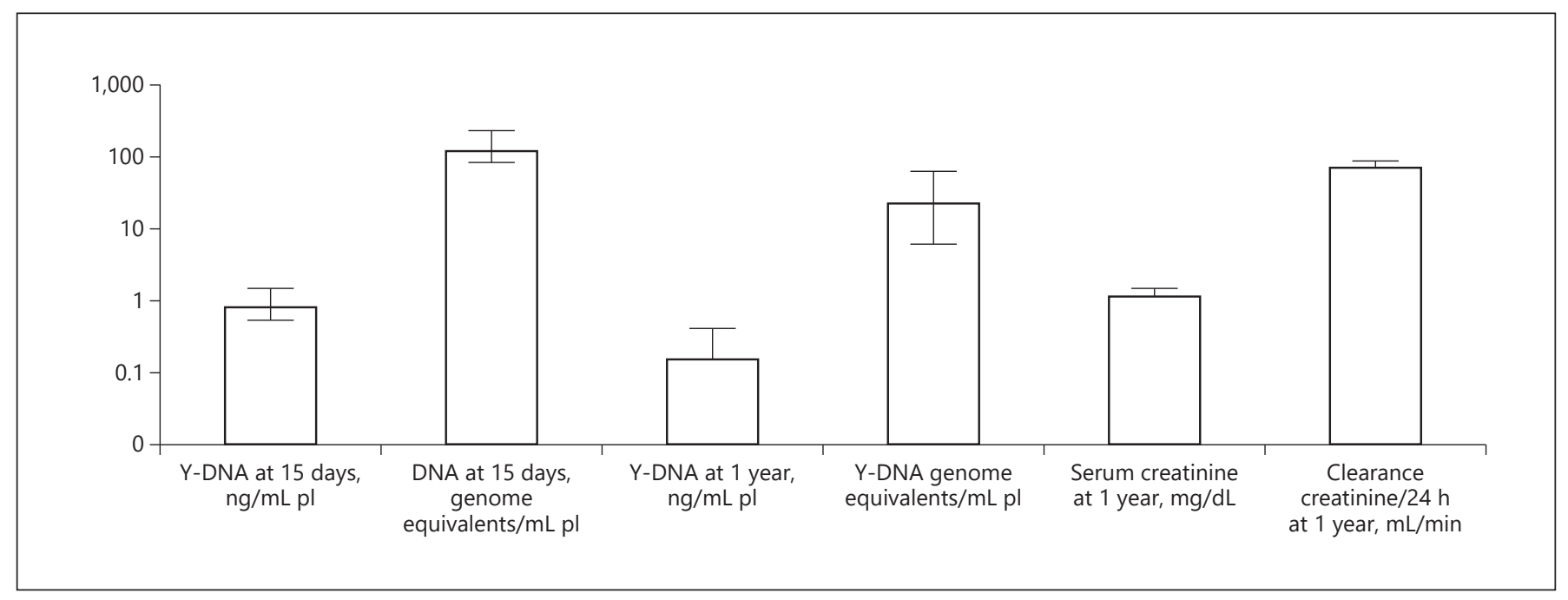

Fig. 1. Laboratory parameters of enrolled patients.

To verify the success of the DNA extraction procedure, we evaluated the total quantity of cell-free circulating DNA (cfDNA) by a qPCR method based on the detection of the single-copy gene APP (Amyloid Precursor protein, chr.21q21.2, accession NM_000484), as reported in a previously published study by Lehmann et al. [15]. With this assay, we detect the total amount of circulating DNA in the blood of the RTR.

qPCR to Quantify Donor-Deriving cfDNA

The qPCR assay for donor-deriving cfDNA was performed as previously reported by Lambert et al. [16], choosing DYS14 (Gene Bank sequence accession number, X06325) as a Y chromosome-specific target sequence. The DYS14 sequence was selected since it is a strictly Y-specific sequence and it is a multiplecopy gene, thus allowing a very sensitive detection of Y-related cfDNA. Each sample was measured in duplicate and the mean quantity of each duplicate was expressed as ng per milliliter of plasma.

Microchimerism in Female Transplant Renal Recipients

\section{Results}

The 12 female patients had no Y-related DNA in pretransplant samples (T0). Donor-specific DNA sequences were present in the plasma of all patients at T1 after kidney transplantation. The mean (SD) plasma Y-related DNA quantity at this time was $0.80(0.69) \mathrm{ng} / \mathrm{mL}$ plasma (median $=0.3$, range $0-3.3$ ) corresponding to a mean (SD) of 121.8 (104.8) genome equivalents $/ \mathrm{mL}$ plasma (median $=45.5$, range $0-494)$. A 5-fold decrease was evidenced in mean (SD) plasma Y-related DNA quantity at T2 after transplantation, which was $0.15(0.26) \mathrm{ng} / \mathrm{mL}$ plasma (median $=0.04$ range $0-0.73$ ), corresponding to $23.1 \pm 40.0$ genome equivalents $/ \mathrm{mL}$ plasma $($ median $=$ 6.1 , range $0-111$ ). It is worth noting that most of the patients under study (80\%) had levels of donor DNA below 
Table 3. Baseline patients' characteristics

\begin{tabular}{|c|c|c|c|c|c|c|c|c|c|}
\hline Pts & $\begin{array}{l}\text { Dialysis } \\
\text { (type) }\end{array}$ & $\begin{array}{l}\text { Age at } \\
\text { transplant, } \\
\text { years }\end{array}$ & $\begin{array}{l}\text { Blood } \\
\text { transfusions, } \\
n\end{array}$ & PRA & DGF, days & $\begin{array}{l}\text { Age at } \\
\text { pregnancy, } \\
\text { years }\end{array}$ & $\begin{array}{l}\text { Miscarriages, } \\
n\end{array}$ & $\begin{array}{l}\text { Male } \\
\text { offspring, } \\
n\end{array}$ & $\begin{array}{l}\text { Follow-up, } \\
\text { months }\end{array}$ \\
\hline 2 & HD & 38 & 3 & 0 & 0 & 25,27 & 0 & 1 & 54 \\
\hline 3 & $\mathrm{PR}$ & 58 & 10 & 0 & 0 & 30 & 0 & 1 & 53 \\
\hline 4 & HD & 70 & 1 & 0 & 0 & 0 & 0 & 0 & 12 \\
\hline 6 & $\mathrm{PD}$ & 52 & 3 & 0 & 0 & $16,20,32$ & 0 & 2 & 43 \\
\hline 7 & $\mathrm{PD}$ & 34 & 2 & 0 & 0 & 20 & 0 & 0 & 37 \\
\hline 8 & HD & 51 & 0 & 0 & 0 & 29 & 0 & 1 & 49 \\
\hline 9 & HD & 60 & 9 & 0 & 7 & 0 & 0 & 0 & 44 \\
\hline 10 & $\mathrm{PR}$ & 59 & 0 & 0 & 0 & 25 & 1 & 1 & 15 \\
\hline 11 & HD & 63 & 5 & 0 & 12 & 25 & 0 & 0 & 12 \\
\hline
\end{tabular}

Pts, patients; PRA, panel reactive antibody; DGF, delayed graft function; HD, hemodialysis; PD, peritoneal dialysis; PR, preemptive transplantation.

10 genome equivalents/mL plasma after 1 year from the intervention. After 1 year from transplantation, all the patients were compliant with follow-up. We observed no graft loss or acute rejection. Mean (SD) serum Cr levels were $1.13(0.35) \mathrm{mg} / \mathrm{dL}$ and mean (SD) e-ClCr was 68.8 (16.9) $\mathrm{mL} / \mathrm{min}$. No kidney biopsies from the 12 RTRs are available. No biopsies were available obviously due to the fact that Cr levels did not increase $>20 \%$, just as a sign for potential correlation to renal function. The values of clinical and laboratory parameters of patients enrolled are shown in Table 2. Figure 1 reports mean plasma Y-related DNA quantity at $\mathrm{T} 1$ and $\mathrm{T} 2$ together with serum Cr levels and $\mathrm{e}-\mathrm{ClCr}$ at $\mathrm{T} 2$.

Mean Y-related DNA quantity at T1 was not significantly different between the non-blood-transfused versus blood-transfused recipient ( $0.74 \pm 1.04$ vs. $0.64 \pm 0.67 \mathrm{ng} /$ $\mathrm{mL}$ ) nor between patients with male offspring versus patients with no male offspring ( $0.58 \pm 0.86$ vs. $0.41 \pm 0.41 \mathrm{ng} /$ $\mathrm{mL}$ ). Patients' baseline characteristics are listed in Table 3 .

\section{Discussion/Conclusion}

MC has grown into a frequently discussed concept, especially in relation to transplantation. Important issues are how MC is induced, for instance, by damage caused by rejection and whether it may enhance recipient tolerance or whether it contributes to or is a sign of the development of chronic irreversible lesions in grafts [17-22]. The consequences of MC are not well understood and are controversial. In transplantation studies, efforts should be made to verify the source of chimeric cell present in the recipients, because these sources may be various, since positive cells may derive from pregnancies and/or blood transfusion $[1,2]$. MC baseline levels, meaning the amount of background chimerism already present before transplantation, were always investigated in our patients to distinguish between "background chimerism" and "transplantation induced MC." The pretransplant blood sample (T0) tested for Y chromosome amplification is an important control as it means that women were negative for circulating male DNA in their plasma from a prior male pregnancy. Therefore, natural MC and iatrogenic MC could not be mistaken. Indeed, generally circulating male MC arising from pregnancy disappears from plasma post-delivery although MC can be maintained at the cellular level. Therefore, if women do not have any circulating male DNA prior to transplantation and have low quantities posttransplantation, we could assume, with low chances to be wrong, that male DNA observed at T1 and $\mathrm{T} 2$ is from the donor $[2,23]$.

Another strong point is that MC detection and quantification by a qPCR method is an accurate and sensitive technique for the measurement of low-level nucleic acid markers. In addition, the DYS14 sequence was selected as a strictly Y-specific multiple-copy gene which allows the achievement of higher sensitivity than single-copy genes, such as the SRY [16]. We observed the presence of donorspecific DNA sequences in the plasma of all patients after 15 days from kidney transplant. Since the DYS14 sequence
Urol Int

DOI: $10.1159 / 000508796$
Villari et al. 
was negative at T0, the development of MC was certainly related to the graft and not to previous transfusion or pregnancies. A marked decrease in plasma DNA donor concentration was recorded after 1 year from transplantation.

The occurrence of MC was associated with good graft outcomes in all our patients since none developed acute rejection or graft dysfunction in the observation period. Our results are in line with other positive experiences observed in the literature $[24,25]$. However, the presence of $\mathrm{MC}$ in the long term and its effects on graft outcomes should be clarified in studies with longer follow-up. Some limitations of our study have to be acknowledged.

The limited number of patients investigated prevents us from reaching definitive conclusions. The technique used to determine the presence of MC (DYS14 assay) is restricted to the detection of male donor $\mathrm{MC}$ in a female recipient. Gender-independent analysis of $\mathrm{MC}$ requires more expensive, sophisticated, and time-consuming approaches requiring genotyping the donor and recipient to establish a unique donor "genetic fingerprint" [26] or genome-wide methylation sequencing [27].

Detection of donor-specific DNA in the plasma of recipient patients has been previously reported by Dennis Lo et al. [3] even in cases with no cellular chimerism in the recipients' blood. The origin of plasma DNA chimerism in these patients could derive from the transplanted organ or donors' hemopoietic cells residing in tissues [3]. On this basis, we concentrated on cfDNA analysis.

No kidney biopsies were available from the 12 patients, with supporting findings related to functional graft. On the other hand, our intent was the development of a minimally invasive approach based just on serial peripheral blood draws for transplantation monitoring.

Our data show good kidney graft outcomes associated with the presence of MC after 1 year of transplantation. However, our analysis does not allow us to study the dynamic of MC in recipients manifesting acute rejection. Therefore, further studies will be needed to investigate the relationship between clinical outcomes and the development of MC in RTR.

There are some limitations to our study that must be acknowledged. We recognized the inherent weaknesses of any single study. The relatively low patient number would affect the power of the study to elucidate our study. Actually, the significance of MC after transplantation is not clear. With our data, it is hard to see if there is an impact of the transplantation outcome, and further investigations on these cases and for longer times $(5,10$, and 15 years) are needed.

\section{Statement of Ethics}

All participants received a detailed description of the study protocol and completed the informed consent process. The protocol was approved by the internal institutional review board. The present trial was carried out according to the ethical principles of the Declaration of Helsinki, following the rules of good clinical practices.

\section{Conflict of Interest Statement}

The authors have no conflicts of interest to declare.

\section{Funding Sources}

This research received no specific grant from any funding agency in the public, commercial, or not-for-profit sectors.

\section{Author Contributions}

Conception and design of the work, Donata Villari; interpretation of data, Francesca Salvianti; interpretation of data, Maria Zanazzi; acquisition of data, Alberto Martini, drafting the work, Pietro Spatafora, acquisition of data; Simone Caroassai Grisanti; analysis of data, Arcangelo Sebastianelli, final approval, Giulio Nicita, Sergio Serni, and Pamela Pinzani.

\section{References}

1 Albano L, Rak JM, Azzouz DF, CassutoViguier E, Gugenheim J, Lambert NC. Chimerism in women with end stage renal diseases: who's who? Chimerism. 2012;3(2):48-50.

2 Albano L, Rak JM, Azzouz DF, CassutoViguier E, Gugenheim J, Lambert NC. Male microchimerism at high levels in peripheral blood mononuclear cells from women with end stage renal disease before kidney transplantation. PLoS One. 2012;7(3):e32248.
3 Lo YM, Tein MS, Pang CC, Yeung CK, Tong KL, Hjelm NM. Presence of donor-specific DNA in plasma of kidney and liver-transplant recipients. Lancet. 1998;351(9112): 1329-30.

4 Lui YY, Woo KS, Wang AY, Yeung CK, Li PK, Chau E, et al. Origin of plasma cell-free DNA after solid organ transplantation. Clin Chem. 2003;49(3):495-6.
5 Starzl TE, Murase N, Ildstad S, Ricordi C Demetris AJ, Trucco M. Cell migration, chimerism, and graft acceptance. The Lancet. 1992;339(8809):1579-82.

6 Sahota A, Gao S, Hayes J, Jindal RM. Microchimerism and rejection: a meta-analysis. Clin Transplant. 2000;14(4 Pt 1):345-50.

7 Pujal JM, Gallardo D. PCR-based methodology for molecular microchimerism detection and quantification. Exp Biol Med. 2008; 233(9):1161-70. 
8 Elwood ET, Larsen CP, Maurer DH, Routenberg KL, Neylan JF, Whelchel JD, et al. Microchimerism and rejection in clinical transplantation. Lancet. 1997;349(9062):1358-60.

9 Varga Z, Gaspert A, Behnke S, von Teichman A, Fritzsche F, Fehr T. Tubular and endothelial chimerism in renal allografts using fluorescence and chromogenic in situ hybridization (FISH, CISH) technology. Pathol Int. 2012;62(4):254-63.

10 Aucamp J, Bronkhorst AJ, Badenhorst CPS, Pretorius PJ. The diverse origins of circulating cell-free DNA in the human body: a critical re-evaluation of the literature. Biol Rey Camb Philos Soc. 2018;93(3):1649-83.

11 Cockcroft DW, Gault MH. Prediction of creatinine clearance from serum creatinine. Nephron. 1976;16(1):31-41.

12 Evaluation of equations that estimate glomerular filtration rate in renal transplant recipients. PubMed-NCBI. Available from: https:// www.ncbi.nlm.nih.gov/pubmed/24721945. Accessed 2020 May 1.

13 Pinzani P, Salvianti F, Orlando C, Pazzagli M. Circulating cell-free DNA in cancer. Methods Mol Biol. 2014;1160:133-45.

14 Lyon HO. News from the Biological Stain Commission No. 5. Biotech Histochem. 2015; 84(3):117-20.
15 Dapson U, Glöckner S, Kleeberger W, von Wasielewski HF, Kreipe H, Kreipe H. Detection of gene amplification in archival breast cancer specimens by laser-assisted microdissection and quantitative real-time polymerase chain reaction. Am J Pathol. 2000;156(6): 1855-64.

16 Lambert NC, Lo YM, Erickson TD, Tylee TS, Guthrie KA, Furst DE, et al. Male microchimerism in healthy women and women with scleroderma: cells or circulating DNA? A quantitative answer. Blood. 2002;100(8): 2845-51.

17 Lagaaij EL, Cramer-Knijnenburg GF, Van Kemenade FJ, Van Es LA, Bruijn JA, Van Krieken JH. Endothelial cell chimerism after renal transplantation and vascular rejection. Lancet. 2001;357(9249):33-7.

18 Gupta S, Verfaillie C, Chmielewski D, Kim Y, Rosenberg ME. A role for extrarenal cells in the regeneration following acute renal failure. Kidney Int. 2002;62(4):1285-90.

19 Mengel M, Jonigk D, Marwedel M, Kleeberger W, Bredt M, Bock O, et al. Tubular chimerism occurs regularly in renal allografts and is not correlated to outcome. J Am Soc Nephrol. 2004;15(4):978-86.

20 Ferlicot S, Vernochet A, Romana S, OrtinSerrano M, Letierce A, Brégerie O, et al. Microchimerism in renal allografts: clinicopathological associations according to the type of chimeric cells. Histopathology. 2010;56(2): $188-97$.
21 Solgi G, Mytilineos J, Gadi V, Paul B, Pourmand G, Mehrsai A, et al. Donor-derived peripheral mononuclear cell DNA is associated with stable kidney allograft function: a randomized controlled trial. Chimerism. 2011; 2(4):102-10.

22 Vamenta-Morris H, Keith DS. Chronic maintenance immunosuppression in renal transplantation: the unrealized goal of improved long-term outcomes. Minerva Urol Nefrol. 2015;67(2):117-38

23 Lissauer D, Piper KP, Moss PA, Kilby MD Persistence of fetal cells in the mother: friend or foe? BJOG. 2007;114(11):1321-5.

24 Kishikawa H, Kinoshita T, Yonemoto S, Kawamura M, Nakazawa S, Ueda N, et al. Early microchimerism in peripheral blood following kidney transplantation. Transplant Proc. 2014;46(2):388-90.

25 Oura T, Hotta K, Cosimi AB, Kawai T. Transient mixed chimerism for allograft tolerance. Chimerism. 2015;6(1-2):21-6.

26 Snyder TM, Khush KK, Valantine HA, Quake SR. Universal noninvasive detection of solid organ transplant rejection. Proc Natl Acad Sci U S A. 2011;108(15):6229-34.

27 Sun K, Jiang P, Chan KC, Wong J, Cheng YK, Liang $\mathrm{RH}$, et al. Plasma DNA tissue mapping by genome-wide methylation sequencing for noninvasive prenatal, cancer, and transplantation assessments. Proc Natl Acad Sci U S A. 2015;112(40):E5503-12. 